\section{Reduction of AOX in the Bleach Plant of a Pulp Mill}

MARIA JOAO M. C. BARROCA, ISABEL M. SECO, PEDRO M. M. FERNANDES, LICÍNIO M. G. A. FERREIRA, AND JOSE ALMIRO A. M. CASTRO*

Department of Chemical Engineering,

The University of Coimbra, Polo II,

Pinhal de Marrocos, 3030 Coimbra, Portugal

The reconfiguration of an existing five-stage bleaching $D_{0} E_{1} D_{1} E_{2} D_{2}$ sequence is proposed to ensure the minimal formation of organochlorine compounds, expressed as AOX, in the bleach plant of a kraft pulp mill processing Eucalyptus globulus wood. This reduction of the load of AOX in the effluents can be achieved without introducing new and expensive technologies in the bleaching process. In practice, this goal can be achieved by eliminating the washing step between the $D_{0}$ and the $E_{1}$ stages. W ith this strategy, the total AOX in the liquid effluent of the bleach plant can be reduced by almost $65 \%$ while maintaining a level of $90 \%$ ISO brightness of the pulp and even diminishing the degradation of its polysaccharides. With this process redesign, the total AOX discharge from the bleach plant can be decreased from 1.2 to $0.42 \mathrm{~kg} / \mathrm{t}$ prior to any biological treatment. Furthermore, the proposed modified $\left(D_{0} E_{1}\right)$ $D_{1} E_{2} D_{2}$ sequence enables the reduction of the total flow rate of effluent to be treated and also the total consumption of water, which is quite critical in these types of plants. Moreover, with this strategy, one is able to move the first drum washer of a conventional bleaching sequence to the entrance of the bleach plant. This gives rise to a cleaner pulp and therefore to lower requirements of chlorine dioxide, which in turn will enable further reductions in the global AOX generation.

\section{Introduction}

In both scientific and industrial communities, there has been a growing interest in the best available technologies for the bleaching of chemical pulpsin order to reduce the discharges of organochlorine compounds in the liquid effluents. This is in response to environmental concerns and government regulations on the limits of these discharges following recognition of their potential adverse biological effects. In the particular case of the bleaching plant of a kraft pulp mill, chlorinated compounds in the effluent can be monitored by several techniques. Among them, the one based on the parameter AOX (adsorbable organically bound halogen) is the most commonly used to characterize and measure their environmental impact. Many approaches to minimize the discharge of AOX from a bleaching plant have been investigated, and in all cases, themain contributionshavefocused on process operations prior to and inside the plant itself. The formation of these substances is mainly attributed to the reactions between the organic matter in the fibers and

* Corresponding author telephone: +351 239798 740; fax: +351 239798 703; e-mail: eqljmc@eq.uc.pt. chlorine that is present in all bleaching processes that are based on chlorineand, to a much smaller extent, on chlorine dioxide. These reactions bind chlorine to the organic matter in the fibers, and these organochlorine products are then removed from the pulp to theliquid phaseduring the process. Concerned with this, several research workers haveevaluated thebleaching operating conditions, particularly in theinitial stages, as a way to decrease the active chlorine and, consequently, thelevels of organochlorine in theliquid effluents. Thus, the reduction of the total charge of chlorine-based chemicals in a conventional five-stage bleaching sequence can be achieved by modifying the pre-delignification stage or by reducing the lignin content of the pulp before entering the bleach plant. These goals can be fulfilled through the combination of several process modifications using existing and newly proven technologies, such as extended delignification in the digestor, oxygen delignification, enzyme pretreatment, modified chlorination stage, and/ or reinforced caustic extraction with oxygen and hydrogen peroxide. Although all thesestrategies are al ready availableto diminish the AOX in the liquid effluent of the bleach plant, the most efficient is the $100 \%$ replacement of elemental chlorine by chlorinedioxidein thechlorination stages sincetheformation of organically bound chlorine decreases al most linearly with increasing chlorine dioxide substitution (1). As shown later by Leibergott et al. (2), it is possible to diminish the AOX in the effluent by $70-80 \%$ and the chlorinated phenolic compounds by $95 \%$ if only chlorinedioxide is used. However, to compensate for the loss in delignification that occurs when elemental chlorine is replaced by chlorine dioxide, several researchers have proposed an oxygen reinforcement of the alkaline extraction stage due to its low capital costs and to makeit easier for implementation with the same equipment. Cook et al. (3) describe modifications in a kraft pulp mill that include the addition of hydrogen peroxide to the oxygenreinforced caustic extraction stage $\left(E_{O P}\right)$ and the oxygen predelignification with short reaction time (Mini-O process) to compensate for the low multiple chlorination. The introduction of these two process changes dropped the AOX from 1.1 to $0.7 \mathrm{~kg} /$ air dried metric tonne (admt).

$\mathrm{Ni}$ etal. (4) showed that the addition of hydrogen peroxide ( $0.1 \%$ on pulp) to an unbleached softwood kraft pulp reduced the AOX formation by about $20 \%$ while maintaining the same delignification obtained without hydrogen peroxide. For an oxygen pre-delignified softwood kraft pulp, bleached with a $D_{0} E_{O} D_{1} E_{2} D_{2}$ sequence, the addition of $6 \mathrm{~kg} / \mathrm{t}$ of hydrogen peroxide led to a total level of AOX below $1 \mathrm{~kg} / \mathrm{t}$ prior to any external effluent treatment (5). Another process described by Cook (6) to reduce the AOX in the effluent is the Ultim-O process, which eliminates the washing of the pulp between the first and the second stages of the bleaching plant. For a three-stage reference bleaching sequence, $\mathrm{D}_{0} \mathrm{E}_{O P} \mathrm{D}_{1}$, the elimination of the washing between the $\mathrm{D}_{0}$ and the $\mathrm{E}_{\mathrm{OP}}$ stages reduced the AOX level to approximately $40 \%$. However, this Ultim-O $\left(\mathrm{D}_{0} \mathrm{E}_{\mathrm{OP}}\right) \mathrm{D}_{1}$ sequence was not capable of producing the same final pulp brightness as that achieved with the referencesequence, $D_{0} E_{O P} D_{1}$. To ensuresimilar strength and optical properties of the pulp with the Ultim-O process, the temperature of the extraction stage $\mathrm{E}_{\mathrm{OP}}$ had to be increased from 70 to $115-130{ }^{\circ} \mathrm{C}$, which in fact is equivalent to an oxygen delignification stage, due to the high temperatures involved. With this $\left(\mathrm{D}_{0} \mathrm{O}\right) \mathrm{D}_{1}$ strategy, the Ultim-O process raises severeapplication problems in an existing conventional bleaching sequence as a result of the associated high temperatureand pressurewith the consequential operational and investment costs. Alternatively, to produce high bright- 
ness pulps with the Ultim-O process and the conventional extraction, it is imperative to reduce the $\kappa$ number of the unbleached pulp by introducing a new oxygen delignification stage prior to the bleaching sequence and/or by extending the cooking process.

The work carried out here is based on a preventive rather than a managerial attitude toward pollution and focuses on the enormous potential that process redesign stills offers to eliminate the generation of toxic chemicals. This cleaner production approach is applied to a conventional industrial five-stage bleaching sequence processing hardwood pulp fibers to $90 \%$ ISO brightness. The purpose of this work is to demonstrate that an adequate reconfiguration of the process, characterized by low capital costs, can lead to very low AOX levels in the effluents while ensuring similar optical and strength properties of the pulp. Despite the similarities with the Ultim-O process, the strategy proposed here examines the situation of bleaching $E$. globulus kraft pulps with a conventional five-stage bleaching sequence, $D_{0} E_{1} D_{1} E_{2} D_{2}$, without the need to install expensive additional hightemperature oxygen delignification systems and the absence of any reinforcement in the first alkaline extraction stage.

\section{Experimental Section}

A given amount $(100 \mathrm{~g}$ ) of an unbleached kraft pulp from $\mathrm{E}$. globulus with a $\kappa$ number of 13.0 and a viscosity of 1365 $\mathrm{dm}^{3} / \mathrm{kg}$ was used in the present study. The pulp sample was fully washed before the bleaching experiments and before $\kappa$ number and viscosity analysis. All bleaching stages of the conventional five-stage sequence were carried out in sealed plastic bags at the desired temperature in a water bath at a consistency of $10 \%$ (mass of oven-dried pulp/mass of suspension). Before each stage, all samples were preheated, and their exact consistency and temperature were regulated with warm distilled water to compensate for the decrease in temperature resulting from the addition of chlorine dioxide or sodium hydroxide solutions. During the first $10 \mathrm{~min}$ of reaction, the pulp was continuously mixed by hand and every $10 \mathrm{~min}$ thereafter. After the prespecified reaction time, a sample of the filtrate was taken with a syringe equipped with a special glass filter to determine the concentration of chemical (chlorine dioxide or hidroxide sodium) and the corresponding values of COD and AOX. This residual concentration of the chemical was analyzed immediately after thermal conditioning, and the COD was measured within $24 \mathrm{~h}$. The filtrate used to carry out the analysis of AOX was acidified to $\mathrm{pH} 2$ with nitric acid and stored at $4^{\circ} \mathrm{C}$ until testing. The AOX and COD of the filtrates from D (chlorine dioxide) and $E$ (alkaline extraction) stages were measured separately. Thechemical oxygen demand of the filtrate(COD) was determined by photometry and is expressed in milligrams per liter. The parameter AOX represents the sum of all organically bound chlorinethatcan beadsorbed on activated carbon under the conditions specified on the Standard Method ISO 9562.

A sample of pulp was also taken, washed twice with 20 times its volume of distilled warm water at $35^{\circ} \mathrm{C}$, and filtered between these two washings. $\kappa$ number, brightness, and viscosity werethen measured usingstandard methods. Next, the remaining pulp was submitted to the following stage of the sequence.

Chlorine dioxidewas produced by reactinga concentrated solution of sodium chlorite with sulfuric acid and collecting the evolving chlorine dioxide gas in cold deionized water. A high chlorine dioxide concentration, noticeable by a dark orange color of the gas, should be avoided because gaseous chlorinedioxideathigh concentration is potentially explosive. Chlorine dioxide solutions were prepared, at most, 1 week before use in a bleaching experiment, and no chlorine was detected in the resultant solution.

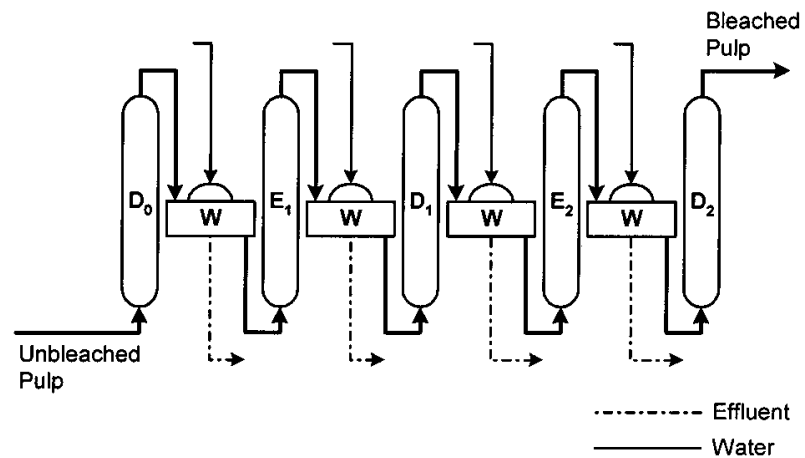

FIGURE 1. Flowsheet of the reference five-stage bleaching sequence, $D_{0} E_{1} D_{1} E_{2} D_{2}$.

TABLE 1. Operating Conditions Used in the Reference Bleaching $D_{0} E_{1} D_{1} E_{2} D_{2}$ Sequence

\begin{tabular}{lccccc} 
& \multicolumn{5}{c}{ stage } \\
\cline { 2 - 6 } operating conditions & $\mathbf{D}_{0}$ & $\mathbf{E}_{1}$ & $\mathbf{D}_{1}$ & $\mathbf{E}_{2}$ & $\mathbf{D}_{2}$ \\
$\begin{array}{l}\text { chlorine dioxide, } \\
\quad 3\end{array}$ & 3 & & 1.7 & & 0.25 \\
$\begin{array}{l}\text { sodium } \mathrm{Cl}_{2} \\
\quad \%\end{array}$ & & & & & \\
$\quad \%$ & & & & 0.6 & \\
temp, ${ }^{\circ} \mathrm{C}$ & 50 & 70 & 70 & 70 & 70 \\
reaction time, min & 30 & 120 & 180 & 120 & 180 \\
pH (final) & $2.5-3$ & $>11$ & $3.5-4$ & $>11$ & $5-6$ \\
\hline
\end{tabular}

Thereferenceindustrial bleaching sequence, $D_{0} E_{1} D_{1} E_{2} D_{2}$, illustrated in Figure 1 comprises a chlorinedioxide oxidation $\left(D_{0}\right)$, an al kaline extraction with sodium hydroxide $\left(E_{1}\right)$, an extra chlorine dioxide oxidation $\left(D_{1}\right)$, followed by a second al kalineextraction $\left(\mathrm{E}_{2}\right)$, and finally by a chlorine dioxidestage $\left(D_{2}\right)$. Between all stages, the pulp is fully washed with cold water followed by extra washing with an excess of warm water.

The operating conditions of this conventional sequence are listed in Table 1. All chemical charges are expressed as percent on oven-dried fiber and the chlorine dioxide charge is expressed as active chlorine $\left(2.63 \times\right.$ mass of $\mathrm{ClO}_{2} / 100 \mathrm{~g}$ o.d. pulp). The full bleaching sequences that last for over 11 h werecarried out without any interruptions in order to better reproduce the industrial conditions.

\section{Results and Discussion}

The reference bleaching sequence gave rise to a pulp with $90 \%$ brightness (ISO) and with a viscosity above $1000 \mathrm{dm}^{3} /$ $\mathrm{kg}$ and required a total consumption of $49.5 \mathrm{~kg} / \mathrm{t}$ of chlorine dioxide (as active chlorine). The total amount of organochlorinecompounds resulting from all bleaching effluents is $1.2 \mathrm{~kg} / \mathrm{t}$, expressed in terms of AOX. At present, the target limit of organochlorine compounds, measured as AOX, imposed by environmental regulations is $1.0 \mathrm{~kg} / \mathrm{t}$ (measured as $\mathrm{TOCl}$ ) after the wastewater treatment plant. Many individual chlorinated compounds are produced by bleaching with chlorine dioxide and/or elemental chlorine, and the amount of this material is characterized as AOX. This organically bound chlorine can be classified in two families of compounds: the first of high molecular weight (MW > 1000) chlorinated lignin and the second of low molecular weight. Thefirst category, which is responsiblefor more than $80 \%$ of the AOX, includes mainly nonaromatic compounds that are hydrophilic and possess low chlorine content. The second category, of low molecular weight, contains a fraction of about $1 \%$ of polychlorinated phenolic compounds (PCPCS) and polychlorinated dibenzo-p-dioxins and -furans (PCDD/ Fs) that are potentially problematic and toxic to aquatic 


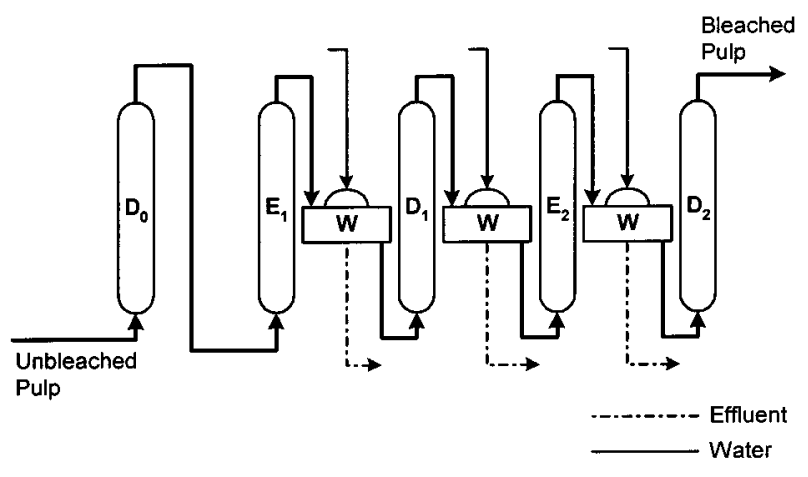

FIGURE 2. Flow sheet of the modified five-stage bleaching sequence, $\left(D_{0} E_{1}\right) D_{1} E_{2} D_{2}$.

organisms due to their ability to penetrate cell membranes or their propensity to bioaccumulate in the fatty tissues of higher organisms (7). However, the bleaching sequence with $100 \%$ of chlorine dioxide and low active chlorine multiple in the oxidative stage, virtually eliminates levels of PCDDs and PCDFs compounds in the final effluent to below analytical detection limits (8-10). The above limit of the environmental regulation can be easily achieved by means of external treatment. However, due to the progressively stricter regulationsimposed by environmental authorities around the world to reduce the discharge of AOX to levels approaching zero, the pulp industry is taking a preventive attitude with respect to this and therefore needs to establish its own strategies to minimize AOX in the liquid effluents. The choice of technology will depend on the feasibility of its implementation and on the corresponding capital and operating costs. Almost all of the chlorinated organic compounds in the effluent of an industrial five-stage sequence are generated in the first chlorine dioxideand alkaline extraction stages of a kraft pulp bleach plant (11); therefore, the most efficient modifications of the process should belooked for in these stages or before the bleaching plant itself. One possible technique would be to create the conditions for destroying the AOX formed during the $\mathrm{D}_{0}$ delignification stage. Thiscan befulfilled in thealkaline extraction process while the pulp is being delignified. Such a goal can be accomplished by allowing the liquid phase leaving the $D_{0}$ stage with the pulp to proceed to the next stage, the al kaline extraction $\mathrm{E}_{1}$, instead of withdrawing it as an effluent in the first washer between the $D_{0}$ and $E_{1}$ towers. This elimination of the washing between the $D_{0}$ and $E_{1}$ stages $\left(D_{0} E_{1}\right)$, the so-called pre-delignification, enables the decomposition of the organochlorine compounds in the alkaline extraction stage, $E_{1}$, by the combined action of the high concentrations of $\mathrm{NaOH}$ and of high temperature. To evaluate the effect of this, a sample of the same unbleached kraft pulp was subjected to a modified bleaching sequence with the same operating conditions of the conventional sequence (Table 1 ) but with no washing between the $D_{0}$ and the $E_{1}$ stages, $\left(D_{0} E_{1}\right) D_{1} E_{2} D_{2}$ (see Figure 2 ). In this experiment, the total charge and the distribution of chlorine dioxide among the acid stages was the same as that used in the conventional sequence, and the final $\mathrm{pH}$ of each stage was maintained within the range described in Table 1 . The $\kappa$ numbers of the pulp after the $D_{0}$ and $E_{1}$ stages for both the conventional and the modified sequences are shown in Figure 3.

It is clear from this figure that elimination of the pulp washing between the $D_{0}$ and the $E_{1}$ stages does not cause any inhibition of the global delignification rate. It is worth mentioning that in the $\left(D_{0} E_{1}\right) D_{1} E_{2} D_{2}$ sequence, a specified portion of pulp was also collected at the end of the $D_{0}$ stage in order to measure its $\kappa$ number, viscosity, and brightness. The values of these last two variables after $D_{0}$ are also very similar for both sequences.

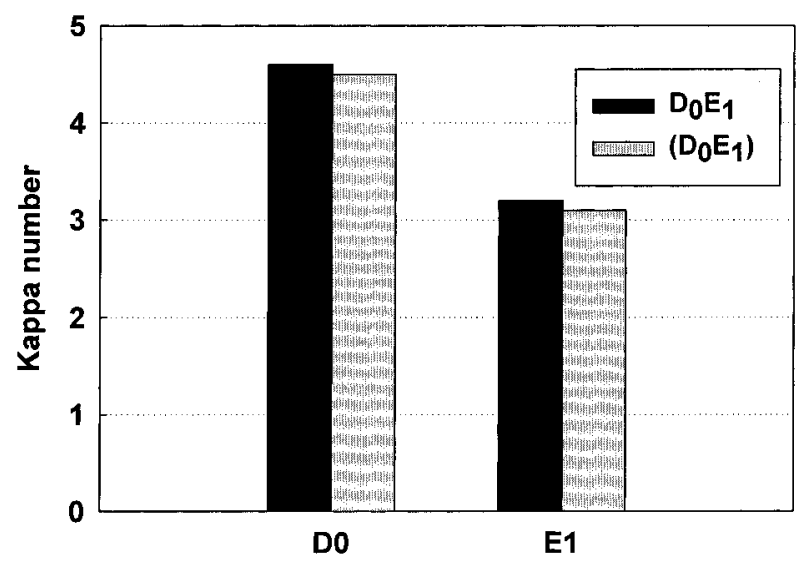

FIGURE 3. $\kappa$ number after $D_{0}$ and $E_{1}$ stages for the reference $D_{0} E_{1} D_{1} E_{2} D_{2}$ and modified $\left(D_{0} E_{1}\right) D_{1} E_{2} D_{2}$ sequences.

TABLE 2. Comparison between the Reference and the Modified Sequence

$D_{0} E_{1} D_{1} E_{2} D_{2} \quad\left(D_{0} E_{1}\right) D_{1} E_{2} D_{2}$

\begin{tabular}{lcc}
\multicolumn{4}{c}{ Final Properties of the Pulp } \\
brightness, \% & 91.9 & 91.9 \\
$\mathrm{PC}$ No. & 0.28 & 0.28 \\
viscosity drop, $\mathrm{dm}^{3} / \mathrm{kg}$ & 190 & 167 \\
\multicolumn{4}{c}{ Total Consumption of Chemicals } \\
$\mathrm{ClO}_{2}$ consumption, as $\mathrm{Cl}_{2}, \mathrm{~kg} / \mathrm{t}$ & 49.5 & \\
$\mathrm{NaOH}$ consumption in $\mathrm{E}_{1}$ stage, $\mathrm{kg} / \mathrm{t}$ & 10.4 & 49.5 \\
total $\mathrm{NaOH}$ consumption, $\mathrm{kg} / \mathrm{ton}$ & 13.8 & 21.9 \\
\hline
\end{tabular}

\section{TABLE 3. AOX Load in the Bleaching Filtrates of Both Sequences}

\begin{tabular}{lcc}
\multicolumn{1}{c}{$\mathrm{AOX}, \mathrm{kg} /$ ton } & $\mathrm{D}_{0} \mathrm{E}_{1} \mathrm{D}_{1} \mathrm{E}_{2} \mathrm{D}_{2}$ & $\left(\mathrm{D}_{0} \mathrm{E}_{1}\right) \mathrm{D}_{1} \mathrm{E}_{2} \mathrm{D}_{2}$ \\
$\mathrm{D}_{0}$ stage & 0.89 & \\
$\mathrm{E}_{1}$ stage & 0.1 & \\
total $\mathrm{D}_{0} \mathrm{E}_{1}$ & 0.99 & 0.23 \\
total sequence & 1.2 & 0.23 \\
& & 0.42 \\
\hline
\end{tabular}

Thefinal properties of thepulp and the total consumption of chemicals in both sequences can be seen in Table 2. This shows that in the two cases the pulp exhibits the same brightness and color reversion (PC number). Nevertheless, the total viscosity drop in the new proposed $\left(D_{0} E_{1}\right) D_{1} E_{2} D_{2}$ sequence is lower than that of the conventional arrangement, revealing a smaller extent of polysaccharides degradation.

The typical industrial charge of sodium hydroxide used in the $\mathrm{E}_{1}$ stage is $20 \mathrm{~kg} / \mathrm{t}$ in order to maintain the $\mathrm{pH}$ above 11. However, as shown in Table 2, the effective consumption in the $E_{1}$ stage is approximately half of the amount initially charged, meaning that the residual alkali is wasted in the al kalineeffluentjust to maintain the final $\mathrm{pH}$ above 11 , which is required for dissociation of almost all the carboxylic acid and phenolic hydroxyl groups. In the sequence without washing between $D_{0}$ and $E_{1}$ stages, $\left(D_{0} E_{1}\right) D_{1} E_{2} D_{2}$, there is an extra consumption of sodium hydroxide to neutralize the acidic carryover in the effluent of the $\mathrm{D}_{0}$ stage. However, the residual alkali is still enough to ensure that the final $\mathrm{pH}$ is above 11.

The elimination of the washing step enabled a reduction of $65 \%$ in the total level of AOX in the effluents. This decrease is illustrated in Table 3 and is due to the fact that almost all chlorinated organic matter in the liquid phase of the main stream leaving the $D_{0}$ stage is hydrolyzed in the extraction stage by the excess of alkali that is usually employed in 
industry. In fact, almost 75\% of the chlorinated organic matter that is generated in the $\mathrm{D}_{0}$ stage as a result of the chlorination of lignin and extractives is eliminated (in terms of AOX) in the extraction stage $E_{1}$.

The proposed $\left(D_{0} E_{1}\right) D_{1} E_{2} D_{2}$ sequence exhibits further advantages over the reference $D_{0} E_{1} D_{1} E_{2} D_{2}$ because itenables the elimination of a stream of acid effluent and consequently the reduction of the total flow rate of filtrates to be treated as well as the total consumption of water. From a process engineering point of view, the most important advantage though is the release of a drum washer after the $D_{0}$ tower, which allows its application in other parts of the process, particularly in reinforcing the washing of the pulp before entering the bleaching plant. This is because, as shown by Barroca et al. (12), the COD of the unbleached pulp plays an important role on the specific consumption of chlorine dioxide during the pre-delignification sequence and therefore on the total amount of organochlorines that are formed. Thus, this redesign of the bleaching process makes it possible to use the spare washer to improve the degree of washing of the pulp stream prior to the bleach plant, reducing the COD level at its entrance. This enables a further decrease in the charge of chlorine dioxide and, thus, of the AOX formation.

\section{Acknowledgments}

The authors are thankful to the Ministry of Science and Technology, through Program PRAXIS, Project No. 3/3.2/ PAPEL/2326/95 for the financial support of this project and for the scholarship granted to M.J.M.C.B. Special thanks are also due to RAIZ, Instituto de Investigação da Floresta e do Papel, for their financial and laboratory assistance.

\section{Literature Cited}

(1) Axegard, P. J. Pulp Pap. Sci. 1986, 12 (3), J67 - J72.

(2) Leibergott, N.; van Leirop, B.; Fleming, B. I. Pulp Pap. Can 1993, 94 (10), T300-T303.

(3) Cook, R. A.; Eagle, A. J.; Gough G. P. Oxygen Delignification Symposium; TAPPI Press: Toronto, Atlanta, 1990; pp 91-99.

(4) Ni, Y.; Kubes, G. J.; van Heiningen, A. R. P.J. Pulp Pap. Sci. 1994 20 (4), J103-J106.

(5) Basta, J.; Anderson, L.; Forsstrom, A.; Wane, G.; Johansson, N.G. New and Improved Possibilities in D100 Bleaching; Proceedings of Pulping Conference; Tappi Press: Atlanta, 1992; pp 547553.

(6) Cook, R. A. Appita J. 1991, 44 (3), 179-183.

(7) Berry, R. M.; Luthe, C. E.; Voss, R. H.; Wrist, P. E.; Axegard, P.; Gellerstedt, G.; Lindblad, P.-O.; Popke, I. Pulp Pap. Can. 1991 92 (6), T155-T164.

(8) Solomon, K.; Bergman, H.; Huggett, R.; Mackay, D.; McKague, B. Pulp Pap. Can. 1996, 97 (10), T345-T354.

(9) Bright, D. A.; Hodson, P. V.; Lehtinen, K.-J.; McKague, B.; Rodgers, J.; Solomon, K. Pulp Pap. Can. 2000, 101 (1), T9-T11.

(10) Weigand, P.; Thacker, W.; Miner, R. Tappi J. 1999, 82 (4), 135144.

(11) Leibergott, N.; van Leirop, B.; Nolin, A.; Faubert, M.; Laflamme, J. Pulp Pap. Can. 1991, 92 (3), T70-T75.

(12) Barroca, M. J. M. C.; Simões, R. M. S.; Castro, J. A. A. M. Appita J., in press.

Received for review January 16, 2001. Revised manuscript received July 17, 2001. Accepted July 25, 2001.

ESO10019H 